\title{
THREAT OR OPPORTUNITY? THE FUTURE OF LIBRARY SERVICES IN THE LIGHT OF TECHNOLOGICAL INNOVATIONS
}

\section{F. W. Lancaster*}

Talk presented at the Universitat Politècnica de Catalunya, March 1992, on the occasion of the first anniversary of the Leibniz Program.

When I was invited to give this talk, I was offered two subjects, one of which was given the title "The Future of Library Services in the Light of Technological Innovations", which is the topic I chose. I find this title to be highly significant because it implies that it is the available technology that determines what library services will look like in the future. This implication - that technological capabilities determine the characteristics of the institution rather than the institution adopting or adapting technology to meet its own goals and objectives- is one that now seems highly prevalent in the library profession. In this talk I will try to assess what technology has achieved for libraries so far and look at possible future developments. In particular, I will attempt to determine tho what extent the future of the library will be governed by technological developments and to what extent the library will be free to mold technology to its own ends.

The title of my talk - "Threat or Opportunity» - derives from a volume of essays that I am now editing. The volume consists of contributions from several eminent librarians, information scientists and other scholars from the United States and elsewhere. The title of the volume is Libraries and the Future: Essays on the Library in the Twenty-first Century. Almost without exception, the authors point out that technological innovations, and other changes in the world around us, can be viewed as a threat to the library or as a rare opportunity for the library profession to make itself more valuable to society than it has ever been before.

First, let us look at what effects technology has had on library and information services so far. In the space of only thirty years, computers and related technologies have come to pervade the operations of libraries and information centers. In considering what has occurred in this time, it is convenient to divide the activities affected by technology into two major groups: the inventory control activities, associated most clearly with circulation and technical service functions, and activities associated with subject access.

Much has happened in automation of the internal functions of libraries and of their resource-sharing activities. Even the smallest of libraries may now have its own computer for circulation and other recordkeeping activities or may belong to some network that offers these services. Multifunctional systems provide comprehensive records on the status of bibliographic items from the time they are ordered to the time they are discarded. Libraries are now linked by vast online networks that make cooperative cataloging a viable proposition, provide up-to-date union

* Graduate School of Library and Information Science, University of Illinois at Urbana-Champaign. Recibido 10-4-92 
catalogs, and greatly facilitate interlibrary lending and other resource sharing activities. Academic researchers can use their own terminals to search a catalog that represents the holdings of many libraries, can determine the availability of an item in any of these, and can generate a request that will cause an item in any library to be charged to them and subsequently delivered to their offices.

Turning to the other obvious area of application of technology, subject access, the changes have been significant. In essentially thirty years we have gone from virtually no databases in electronic form to several thousand, many readily accessible through online networks. These databases include bibliographic records, numerical and directory-type information, and full text. They can be accessed directly, at moderate cost, by scholars, or by the general public, from offices, libraries or from the home. So-called "user friendly" interfaces have been designed to help the inexperienced database user to perform useful searches without the assistance or intervention of an information specialist. The card catalog is dead or dying. Online catalogs of the holdings of a library, or a network of libraries, can also be searched from offices or from the home.

Since online catalogs accessible to the public, OPACs, have fallen into place, the proportion of searches that are subject searches seems to have increased, and librarians are now enthusiastic about the potential of OPACs for greatly increasing the power of subject searching. Some libraries are now expanding their catalogs to include access to items, such as periodical articles, that have not traditionally been included, or to provide access to library-compiled databases of specialized local resources.

In terms of library "philosophy", the most obvious change that has occurred as a result of technological innovations is expressed concisely in the phrase "access rather than ownership». That is, librarians have come to recognize that they can no longer collect everything their users may need, nor should they. Instead, their role is to provide access to resources, in whatever form they may exist, as and when the need for these resources arises. Clearly, this has important implications for the financing of libraries since the bodies that provide the funds must accept that, in the future, libraries are less likely to have tangible artifacts to show for their money.

Having very briefly reviewed the changes brought about by technology so far, let us look at what may occur in the future. What, for example, is said by the authors contributing to the volume I am now editing?

The contributors represent a wide variety of libraries and related institutions in four continents. With such diversity of background, it was to be expected that the visionary statements would exhibit great differences. In fact, there is considerable agreement in some areas.

Dave Penniman (1) stresses that libraries must be active, not passive, emphasizing the delivery of information rather than its storage, and that they should be evaluated on the basis of services delivered, not assets controlled. Writing as the President of the Council on Library Resources, he claims that we must focus our energies on research partnerships that ensure that libraries become the information delivery systems needed in the future and that the profession will have the leadership skills necessary to make them essential delivery systems. At present, he suggests, libraries are in jeopardy because they lack true leadership. 
Dealing with the academic library environment, Pat Molholt (2), a prominent academic librarian, puts the emphasis of her paper on technological developments. She argues that the increasing power and sophistication of information technologies, which threaten the existence of the "traditional» library, could in the future make the institution and the profession of greater value than ever before. She agrees with Penniman that changes need to occur in the profession:

The technologies of networking and distributed information resources, of nonlinear programs accommodating rich linking among information resources, and the movement toward cinematic and interactive systems will change what libraries are and what librarians do. We need to plan for a change in emphasis from being the keepers of the book to being guides through the universe of knowledge... The ability of librarians to be imaginative, to move outside of the library and into broader information roles will be a measure of the future librarian.

Ken Dowlin (3) and Philip Young (4), representing public and academic libraries respectively, show considerable agreement with Penniman and Molholt in that they, too, stress the need for change in the profession. The metaphors used by these various authors may differ but the message is much the same. Dowlin views the present library as a «fortress» when, in fact, it should be a «pipeline». Like Penniman, he sees a danger that we are not producing the leaders needed to transform the library from fortress to pipeline. Our library schools are producing graduates at the level of the skilled craftsman or general contractor but they are not producing the architects of vision.

Dowlin constructs his vision of the future of the public library from plans for the development of his own library, the San Francisco Public Library. This will in no sense be the "library without walls" predicted by some writers (myself included!). Indeed, the building will be an «intelligent» one that includes video and audio studios capable of "exporting" library services into the home. He expects that, by the year 2000 , every home in the city will be connected to the library by cable television or telephone lines and that the building will be the uhub of a community network». Dowlin believes that electronic technology can provide users with a library that has the «ambience and sense of community of a small town" and, at the same time, allows for instantaneous global connections.

Young emphasizes that libraries will have to provide information in whatever format is most appropriate to the user - print, electronic, optical, or some format yet to be envisioned. Parenthetically, it is worth noting that most contributors to this volume do not see the new formats as replacing the old but, rather, as existing side by side with them.

Young believes that the ultimate goal of the profession is the creation of a "virtual library", consisting of "the sum total of accessible information available anywhere». In this scenario, the physical library building becomes merely a «retrieval node».

David Raitt (5) reviews the information technologies available today, or likely to be available in the near future, and claims that an important role of the librarian must be the evaluation of appropriate technology and the education of others on the capabilities of this technology. At present, this technology is not 
being developed by the disseminators of information but by a «parallel information industry" (mostly the computer and entertainment industries). He implies that librarians need to be more active in determining how the technologies will be used.

Presenting a British perspective, Maurice Line (6) agrees with Penniman that libraries must be evaluated in terms of the services they provide, not the collections they own. He claims that technology will make the library «less of a place to which people come and more of a resource that can be used remotely". It is worth noting that most of the authors agree that libraries as institutions, and even library buildings, will continue to exist, but that their roles will change somewhat.

The less developed countries are represented in this volume by papers from Professor Neelameghan (7) and Jeannette Kremer (8). Neelameghan feels that technology will have great beneficial impact on even the Third World nations. Libraries there will be able to "provide access to a wider range of information through networks at the national, regional and international levels and by using databases in electro-optic media, e.g., CD-ROM». Focusing on the Brazilian situation, Kremer, while she does not discredit the potential role of technology, emphasizes that libraries and information services will develop in that country to the extent that they can demonstrate their value in meeting national social, technological and cultural demands. Put somewhat differently, technology may well help even Third World libraries to achieve their goals, but the implementation of new technologies should not become a goal in and of itself.

Fred Kilgour's (9) view of the library of the future is less conventional than that of many of the other contributors. He visualizes an electronic library system consisting of a centralized database of full text (of books, articles and other items) with remote library access databases that provide various indexes to this full text.

It is perhaps somewhat ironic that the most radical departure from the present type of library is predicted by a scholarly user of libraries (Lauren Seiler) rather than by a librarian, although he is aided and abetted in this by a professor of library and information science (Tom Surprenant). Seiler and Surprenant (10) claim confidently that the end of the print library is in sight and that print on paper is becoming extinct. They go on to describe a library world in which all sources of information, inspiration and entertainment are electronic; they describe the "virtual information center" that Philip Young suggests may be the ultimate goal of the library profession. In the virtual information center, shelves of books are replaced by images of shelves of «books» and each user can browse electronically through essentially the world's store of recorded knowledge without leaving home.

Let us now turn to another set of forecasts: Information UK 2000, edited by John Martyn, Peter Vickers and Mary Feeney (11). This volume presents the results of a study initiated by the British Library to look at the way information is likely to be generated, stored and handled in the next decade or so. The study was to look at the subject from more than a technological perspective, also taking in social, economic and related issues. Planning for the project began early in 1989 and most of the data gathering occurred late in 1989 and early in 1990.

The study is based on inputs solicited from around sixty «subject experts» organized into a series of eleven task forces. Each member of a task force prepared an individual forecast. These were then combined to form a consolidated forecast 
for each area. Some contributions from individuals not members of the task forces were also obtained.

Eleven of the fifteen chapters of the book consist of the task force reports. These are preceded by an introduction and an overview (a kind of executive summary) and followed by two implications and recommendations chapters. The task force reports deal with the following areas: technology; archives, libraries and information services (the shortest of the task force reports, at around ten pages, which suggests that libraries and traditional information services were not considered too important in the «big picture»); recording and reproducing; communications infrastructure; publishing, new products, distribution and marketing; individual and domestic uses of information; organizations and their use of information; manpower, education and training; issues for information users; issues of policy from the policy-makers' viewpoint.

The book contains too many projections, especially in the areas of technology, to allow one to summarize effectively. Since we are most interested in the forecasts that relate to libraries and the future of the library and information science profession, it is these that will be looked at most closely. It is predicted that budgetary constraints will cause a shift from purchase of materials to purchase of access, that a "super-league" of very large libraries will emerge as the basis of the holdings that other libraries will access, and that local libraries will primarily become switching centers. There is nothing too startling here. In fact, forecasts of this type can be traced back about twenty years. A more controversial prediction is that academic libraries in general will decline. Academic departments will provide their own access to electronic resources and the academic library will become little more than a study hall.

Turning to education and training, it is predicted that opportunities for employment in "traditional" settings (presumably libraries) will decline but that new types of positions will emerge. These include:

Research and information analysis in support of decision-making and policy formulation, and information design, ranging from technical writing to a responsibility for the management and design of an organization's overall information production activity... There will be an increase in the numbers of consultants and intermediaries.

(Page 29)

It is predicted that a shift away from formal training in library and information science will occur and that future curricula will deal more with information technology and management and less with «social aspects».

The editors of the report, in their recommendations, see the library and information profession, as it now exists, as threatened:

More widespread use of technology, more automation, more computer literacy among the population at large, greater commercial pressures to sell information products of various kinds to the public, all these factors will tend to weaken the position of the traditional librarian or information scientist. (Page 262) 
Despite drawing on around sixty «experts", there are some very surprising omissions in the forecasts. If anything has emerged clearly in the hundreds of user studies completed over the last thirty years it is that users of information products want greater selectivity - more «quality filtering». Although the editors do say that "customers will have higher expectations of information service suppliers" (page 20), the whole quality aspect is virtually ignored. The term «quality» does not even appear in the subject index.

The greatest defect of this study is the fact that it seems to rely primarily on technological solutions to the problems of information access and dissemination. This is all the more surprising in that a number of studies performed in the United Kingdom have raised serious doubts as to whether technological solutions have really improved subject access at all, and one of these was performed by the senior editor of the volume. The studies in question can be summarized as follows:

John Martyn (12) has compared the results of his recent survey of research scientists with the results obtained in a similar survey he performed more than twenty years earlier. The later survey indicates greater awareness of the importance of information, and greater use of information-gathering methods, but no corresponding increase in the perceived usefulness of the methods. More significantly, the number of cases in which scientists discover relevant information too late to be of maximum value to them seems to be increasing rather than decreasing.

P. S. Davison, et al. (13) report on the results of searching techniques used to compile a comprehensive database on costs and modelling in information retrieval. Forty different sources were drawn upon and 6098 relevant items were located. Of these, however, about two-thirds were unique to only one source and thus missed by the other 39 . Printed bibliographies were found to be the most productive sources and the online search of databases gave the worst results (only $5 \%$ of the relevant references retrieved).

Margaret Slater (14) mailed several thousand questionnaires to professionals in the fields of engineering, chemistry and insurance to study their use of library and information services in the corporate setting. Respondents were asked to rank sixteen departments or services within the company in terms of their importance to the organization. Chemists put the library in the tenth position out of sixteen departments and online searching facilities in the fifteenth position. Engineers put the library in the twelfth position and online searching in the fourteenth, while the professionals in insurance put online searching in the thirteenth position and the library in the fifteenth. For those in insurance only sports and recreation ranked below the library in value to the company. For engineers, only sports and recreation, online searching and the canteen (i.e., restaurant or cafeteria) ranked below the library.

None of these studies offers much evidence that technology has greatly increased access to information, or that the image of librarians and other information professionals has improved considerably in the computer era, so why place so much emphasis on technological solutions?

Of course, we do not yet know which of the various visions, put forward by librarians and others, will prove most «correct». That in itself is not too important. 
What is important is that significant changes will occur in the way in which sources of information, inspiration and entertainment will be made available and that these changes will have a rather major impact on the library and on the library profession.

It is obvious that many changes are taking place in the environment within which libraries function and that the future of the library will, to a very large extent, be governed by developments outside the library's immediate control. The most obvious factor influencing the future of the library will be what occurs in the publishing industry and in the entire system of scholarly communication. It seems clear that more and more information resources will be published in electronic form and that conventional print on paper will decline in importance. What is less clear is how these electronic information resources will be made available: accessible through electronic networks or distributed as physical artifacts such as CDROM or other forms yet to be devised. Distributed electronic forms can be acquired by libraries in much the same way that printed sources are acquired, but resources that are only accessible through electronic networks present the library with a different set of problems and put the library in a somewhat different role as an information provider.

The shape of the library of the future will also be determined by the shape of the institution of which it forms a part. In the United States we seem to be moving rapidly toward an «electronic university», one in which much of learning and scholarly communication will take place through electronic media. David Lewis (15), Lehman Librarian at Columbia University, has discussed the implications of this for the academic library of the future. He points out that the automation of old systems is not enough; the complete restructuring of institutions will be needed. Moreover, users will demand more from the library than they have in the past:

Students may expect the library to be as powerful and easy to use as electronic teaching tools. Unfortunately, libraries are rarely easy to use. If analysis with new computer tools becomes easier and more productive than library research, students can be expected to use the new tools rather than the library. If libraries do not improve their services so that they remain an essential teaching tool, they risk becoming irrelevant to the teaching process. If this is allowed to happen, it is easy to predict a decline in library funding.

(Page 293)

I would now like to turn to one manifestation of technology that is sometimes seen as the solution to all library and information service problems, namely, artificial intelligence and/or expert systems.

Any discussion of applications of artificial intelligence is hampered by the fact that no universally accepted definition of the term seems to exist. Indeed, several of the books written on artificial intelligence make no real attempt to define it. [The objective of artificial intelligence is at least well illustrated by Kurzweil (16), quoting Elaine Rich, as how to make computers do things at which, at the moment, people are better.] An even worse problem is the fact that the term is used so carelessly, often referring to operations (e.g., human selection from a computerdisplayed menu) in which no machine intelligence is involved at all. It is ironic that 
work of the type performed by such pioneers as Luhn and Baxendale, in the late 1950 's and early 1960 's, on automatic indexing by extracting words from text using frequency criteria, then considered an application of computational linguistics, should now be considered an artificial intelligence (AI) application.

While not a formal definition, perhaps, Fenly (17) has offered a clear and concise statement that illustrates what $\mathrm{AI}$ is, or should be, all about:

...computer programs have been developed which exhibit human-like reasoning, which may be able to learn from their mistakes, and which quickly and cleverly perform tasks normally done by scarce and expensive human experts.

(Page 52)

In other words, one can say that AI attempts to develop systems that perform some of the tasks normally performed by experts in some area; perhaps the most obvious example is medical diagnosis. For this reason, systems of this type are frequently referred to as expert systems. The terms knowledge-based systems and rule-based systems seem now to be used more or less interchangeably with expert systems. The reason is, of course, that systems of this type must be given a body of knowledge (e.g., symptoms and signs associated with a particular disease state) to work on and some of these knowledge bases would consist of rules, such as rules for descriptive cataloging.

Because descriptive cataloging is rule-based, one would think that this activity would be a prime candidate for an expert systems application, and some work has been done in this area (e.g., Schwarz (18); Weibel (19); Jeng (29); Borko and Ercegovac (21). Fenly (17), however, claims that the results have so far been unconvincing. He feels that a cataloging system with genuine expertise is an order of magnitude more difficult to implement than one that merely casts cataloging rules in an automated format. As he points out:

...genuine expert systems, with the depth and power to solve substantial and meaningful problems, are time-consuming and costly to develop...

( Page 54)

Fenly does suggest, however, that there may exist certain descriptive cataloging problems that require an unusual amount of intellectual effort and that problems of this type might justify the expense of a full expert-systems approach. One such application is that of the cataloging of series.

Weibel (19) seems to agree with Fenly to a very large extent. Although he, himself, has performed research at OCLC on the feasibility of automatic descriptive cataloging from images of title pages, he sees a "thread of unreality" in much of the research performed in this area so far. He claims that there exist «large obstacles to implementation of production systems" and that expert system techniques are «unlikely to change technical processing in the library in the next five years"s. However, like Fenly, he seems to believe that certain specialized tasks in cataloging might benefit from an expert-systems treatment. In his view, it is more important that automated approaches to cataloging should be «intelligently implemented» than that they be «intelligent». 
The assignment of terms to documents, to represent the subjects dealt with, is another activity that might benefit from the application of artificial intelligence. While subject indexing cannot be as rule-based as descriptive cataloging, certain rules do have to be followed. In very large systems, such as those operated by the National Library of Medicine, these rules could be quite extensive. For example, one set of rules prescribes which subheadings can be used with which categories of main headings.

An interactive program, MedIndEx, is being developed at the National Library of Medicine, using expert system principles, to assist the indexer in using Medical Subject Headings to represent the subject matter of biomedical articles. Work on this system is reported by Humphrey (22). In essence, the system can perform two major tasks: prompt the indexer to assign a particular term or type of term, and correct the indexer when he or she uses a term inappropriately.

Other approaches to automatic indexing or comptuter-aided indexing, described in the literature, also claim to use artificial intelligence or expert system techniques. However, it is difficult to understand how systems that assign terms to documents on the basis of similarity between words occurring in document text (e.g., titles and abstracts) and in word "profiles" associated with the terms can be regarded as involving artificial intelligence. On the other hand, artificial intelligence could be involved if the indexing system learned from its mistakes and was thus able to improve its own performance.

A lot of work has been done on the development of «intelligent front-ends» or «intelligent interfaces» to aid the exploitation of databases through online networks. For example, Hu (23) has evaluated one such interface designed to help someone select the database that appears most appropriate to use to satisfy a particular information need. Hu's study indicates that this particular interface operates almost entirely through the use of menus, from which the user makes a selection, and that it exhibits no evidence of any real "intelligence» in database selection.

Other interfaces are designed to help a user construct a search strategy that appropriately reflects his information need. Several interfaces of this type have been reviewed by Vickery (24) and by Alberico and Micco (25). Some of these operate largely through menus, some prompt the user by asking him questions designed to usefully limit the scope of the search, and some will accept input from the user in the form of a narrative statement of information need. While many of these are ingenious and useful tools, it is not clear that they can actually be said to involve the use of artificial intelligence.

The universal question-answering device envisioned by Dana (26) has not yet been achieved, but some progress has certainly been made toward the development of systems that will at least tell a library user which reference source to consult to answer a particular question. A good example of such a system is Answerman (Waters, (27)), developed at the National Agricultural Library. In this system, menus are used to narrow the scope of the user's question and to lead to the type of tool (directory, gazetteer, specialized dictionary, and so on) needed to answer the question. Through these menus, the user can be led to a particular source of information that is likely to contain the needed answer. Waters (28) considers question answering to be an obvious application of expert system approaches 
because similar questions are repeated time and time again and because some libraries record questions received and answers supplied, thus creating an appropriate «knowledge base». Parrott (29) has prepared a comprehensive review and typology of expert systems designed to assist the reference process in libraries.

Many years ago, when Luhn (30) first described an approach to the Selective Dissemination of Information (SDI) using computers, he envisioned a system that would learn from its mistakes. The profiles of interest of participants in the SDI program would automatically be modified in response to their evaluations of the notifications received. Terms appearing in the profiles would be upweighted or downweighted depending on whether they were associated with items judged by the recipient to be useful or not useful. Carried to its logical conclusion, a term would automatically be deleted from a profile if the SDI recipient repeatedly rejected as «irrelevant» the items retrieved by this term. Luhn's automatic approach to profile updating was found to be difficult to implement and was never fully adopted in an operating system. In principle, there is no reason why it should not work. If it did, such a system could be said to exhibit intelligence because it learns from its mistakes.

Very few of the systems referred to as «expert» or as incorporating «artificial intelligence", in the library context, appear to have any true learning features. A notable exception is an application described by Pontigo et al. (31). The system described is designed to decide from which source a particular book or other item should be ordered, or at least to help the librarian make such a decision. The knowledge base used ties document identifiers (e.g., ISBN's and technical report numbers) to probable sources of supply. The system is said to be "dynamic and adaptive»: data on success rates in acquiring particular types of materials from particular suppliers can be fed back to update the knowledge base and thus to improve the probability that a particular item will be available from the supplier selected.

Fenly (17) has usefully summarized the potential benefits of expert systems as these have been identified in the literature. They include:

1. Make scarce expertise more widely available, thereby helping non-experts achieve expert-like results.

2. Free some of the time of human experts for other activities.

3. Promote standardization and consistency in relatively unstructured tasks.

4. Provide incentives for creating a database of knowledge in a permanent form (e.g., not dependent on the availability of particular individuals).

5. Perform at a consistently high level (e.g., not influenced by fatigue or lack of concentration).

These benefits are very real and there seems little doubt that carefully designed knowledge-based systems could be of great value to the library profession when applied to highly specialized activities that are now accomplished only through the expenditure of significant amounts of the time of expensive human experts. They could also be of value in tasks, such as the document ordering activities dealt with by Pontigo et al., that can obviously benefit from learning capabilities. However, there is little to support the belief that equipment with "intelligence» will soon be able to take over many of the intellectual tasks now performed by a well trained 
and experienced librarian, and many writers on this subject seem much too optimistic on this point. For example, Metzler (32) has said:

The library of the future may be able to provide a far richer access to, and utilization of, the knowledge contained (often implicitly) in its collection. The most immediately feasible development along this line would be content-based information retrieval. This, of course, would require a far more general and robust brand of artificial intelligence and natural language understanding than what we have available now. The step beyond that would involve not only understanding text well enough to determine whether it is relevant to a general information need expressed by a user, but to understand it well enough to actually extract information that can be used by a program.

(Pages 8-9)

The enthusiasm for AI that exists in some segments of the library profession today reminds one of the enthusiasm for machine-aided diagnosis that existed in some segments of the medical profession about twenty years ago. Machine-aided diagnosis has not been widely accepted by the medical community. It is now realized that the problems are much greater than they once appeared to be. Human experts operate through a combination of knowledge, experience and intuition. Capturing the knowledge in some electronic form is possible, if not exactly easy, but recording human experience is a problem of a greater order of magnitude, and the replacement of human intuition is unlikely to be achieved for a very long time.

Most of the activities performed by librarians require less knowledge, experience and intuition than does medical diagnosis. Nevertheless, the problems involved in automating even the "simplest" of intellectual tasks are frequently underestimated. As Fenly (7), quoting Davies (33), has rightly pointed out:

The expertise in cataloging is not explicit in the rules; rather, it is implicit in the heuristics employed by the experts who do the work.

(Page 58)

Similarly, Weibel (19), referring to work performed by Borko and Ercegovac (21) on the cataloging of maps, points to their conclusions that necessary expertise in such procedures "extends beyond that which is articulated in formal rule sets» and that the complexity of the activity militates against the application of an expert systems approach.

I would like to close my talk with some words of warning. While it is true that technological developments have put some important new tools into the library and into the hand of librarians, these tools have not necessarily been used wisely or imaginatively within the profession. For example, automated circulation systems are seen as labor-saving devices and means for checking books out more cheaply or rapidly rather than as management information systems, as important tools in collection analysis and development; and online catalogs are really no more than card catalogs in electronic form. We have not produced a completely new tool but merely automated an existing one. 
More importantly, perhaps, librarians have become too much enamored of the technology available to them. Automation of library services has become an objective in and of itself. At the same time, librarians have lulled themselves into a false sense of security - into the belief that technology can and will solve all our information access problems and that, merely by adopting technological solutions, the librarian will gain in prestige and status.

The fact is, of course, that the true intellectual tasks associated with the library profession - subject analysis, interpretation of information needs, search strategy, and suchlike - are not easily delegated to machines. Whatever may happen to the library as an institution (i.e., as a collection of physical artifacts), it seems unlikely that the expertise of the skilled librarian will be replaced by AI or any other technology in the foreseeable future. As Horton (34) has stated so eloquently:

...creativity, talent, and brainpower... are the real «capital assets» of the Information Economy, not information handling machines.

(Page 39)

Threat or opportunity? The most alarming thing that emerges from the essays contributed to the volume I am editing is that some of our most respected and senior librarians seem to feel that the library profession lacks the leadership needed to turn these changes to its advantage.

\section{References}

1. PENNIMAN, W. D. Shaping the future for libraries through leadership and research. In: Libraries and the Future: Essays on the Library in the Twenty-first Century; ed. by F. W. Lancaster. To be published in 1992 by Haworth Press.

2. MOLHOLT, P. Libraries as bridges, librarians as builders. In: Libraries and the Future: Essays on the Library in the Twenty-first Century: ed. by F. W. Lancaster. To be published in 1992 by Haworth Press.

3. DOWLIN, K. E. The neographic library. In: Lihraries and the Future: Essays on the Library in the Twenty-first Century; ed. by F. W. Lancaster. To be published in 1992 by Haworth Press.

4. YOUNG, P. H. Visions of academic libraries in a brave, new future. In: Libraries and the Future: Essays on the Library in the Twenty-first Century; ed. by F. W. Lancaster. To be published in 1992 by Haworth Press.

5. RAITT, D. The library of the future. In: Libraries and the Future: Essays on the Library in the Twenty-first Century; ed. by F. W. Lancaster. To be published in 1992 by Haworth Press.

6. LINE, M. B. Libraries and information services in 25 years' time: a British perspective. In: Libraries and the Future: Essays on the Library in the Twenty-first Century; ed. by F. W. Lancaster. To be published in 1992 by Haworth Press.

7. NEELAMEGHAN, A. Libraries and information services in Third World countries. In: Libraries and the Future: Essays on the Library in the Twenty-first Century; ed. by F. W. Lancaster. To be published in 1992 by Haworth Press.

8. KREMER, J. M. Perspectives for information services and professionals in Brazil. In: Libraries and the Future: Essays on the Library in the Twenty-first Century: ed. by F. W. Lancaster. To be published in 1992 by Haworth Press.

9. KILGOUR, F. G. The metamorphosis of libraries during the foreseeable future. In: 
Libraries und the Future: Essays on the Library in the Twenty-first Century; ed. by F. W. Lancaster. To be published in 1992 by Haworth Press.

10. SEILER, L. H.; SURPRENANT, T. T. The virtual information center: scholars and information in the 21st century. In: Libraries and the Future: Essays on the Library in the Twenty-first Century; ed. by F. W. Lancaster. To be published in 1992 by Haworth Press.

11. MARTYN, J. et al., eds. Information UK 2000. London, Bowker-Saur, 1990.

12. MARTYN, J. Literature Searching Habits and Attitudes of Research Scientists. Boston Spa, British Library, 1989.

13. DAVISON, P. S., et al. International Bibliographic Review on Costs and Modelling in Information Retrieval. Boston Spa, British Library, 1988.

14. SLATER, M. Non-use of Library Information Resources at the Workplace. London, Aslib, 1984.

15. LEWIS, D. W. Inventing the electronic university. College and Research Libraries, 49, 1988, 291-304.

16. KURZWEIL, R. Machine intelligence: the first 80 years. Library Journal, 116 (13), August 1991, 69-71.

17. FENLY, C. Technical services processes as models for assessing expert system suitability and benefits. In Artificial Intelligence and Expert Systems: Will They Change the Library? Proceedings of the 27th Annual Clinic on Library Applications of Data Processing; ed. by F. W. Lancaster and L. C. Smith, pp. 50-66. Urbana, University of Illinois, Graduate School of Library and Information Science, 1992.

18. SCHWARZ, H. Expert systems and the future of cataloguing: a possible approach. LIBER Bulletin, 26, 1986, 23-50.

19. WEIBEL, S. Automated cataloging: implications for libraries and patrons. In: Artificial Intelligence and Expert Systems: Will They Change the Library? Proceedings of the 27th Annual Clinic on Library Applications of Data Processing; ed. by F. W. Lancaster and L. C. Smith, pp. 67-80. Urbana, University of Illinois, Graduate School of Library and Information Science, 1992.

20. JENG, L. H. An expert system for determining title proper in descriptive cataloging: a conceptual model. Cataloging and Classification Quarterly, 7 (2), 1986, 55-70.

21. BORKO, H.; ERCEGOVAC, Z. Knowledge-based descriptive cataloging of cartographic publications. In: Annual Review of OCLC Research, July 1988-June 1989; pp. 49-50. Dublin, OH, OCLC, 1989.

22. HUMPHREY, S. M. Interactive knowledge-based systems for improved subject analysis and retrieval. In: Artificial Intelligence and Expert Systems: Will They Change the Library? Proceedings of the 27th Annual Clinic on Library Applications of Data Processing; ed. by F. W. Lancaster and L. C. Smith, pp. 81-117. Urbana, University of Illinois, Graduate School of Library and Information Science, 1992.

23. HU, C. An Evaluation of Online Database Selection by a Gateway System with Artificial Intelligence Techniques. Doctoral dissertation. Urbana, University of Illinois, Graduate School of Library and Information Science, 1987.

24. VICKERY, B. C. Intelligent interfaces to online databases. In: Artificial Intelligence and Expert Systems: Will They Change the Library? Proceedings of the 27th Annual Clinic on Library Applications of Data Processing; ed. by F. W. Lancaster and L. C. Smith, pp. 239253. Urbana, University of Illinois, Graduate School of Library and Information Science, 1992.

25. ALBERICO, R.; MICCO, M. Expert Systems for Reference and Information Retrieval. Westport, CT, Meckler, 1990.

26. DANA, J. C. Libraries: Addresses and Essays. White Plains, NY, H. W. Wilson Co., 1916.

27. WATERS, S. T. Answerman, the expert system specialist: an expert system for retrieval of information from library reference books. Information Technology and Libraries, 5, 1986, 204-212. 
28. WATERS, S. T. Expert systems at the National Agricultural Library: past, present, and future. In: Artificial Intelligence and Expert Systems: Will They Change the Library? Proceedings of the 27th Annual Clinic on Library Applications of Data Processing; ed. by F. W. Lancaster and L. C. Smith, pp. 161-177. Urbana, University of Illinois, Graduate School of Library and Information Science, 1992.

29. PARROTT, J. R. Reference expert systems: foundations in reference theory. In: Artificial Intelligence and Expert Systems: Will They Change the Library? Proceedings of the 27th Annual Clinic on Library Applications of Data Processing; ed. by F. W. Lancaster and L. C. Smith, pp. 118-160. Urbana, University of Illinois, Graduate School of Library and Information Science, 1992.

30. LUHN, H. P. Selective Dissemination of New Scientific Information With the Aid of Electronic Processing Equipment. Yorktown Heights, NY, IBM Advanced Systems Development Division, 1959.

31. PONTIGO, J. et al. Expert systems in document delivery: the feasibility of learning capabilities. In Artificial Intelligence and Expert Systems: Will They Change the Library? Proceedings of the 27th Annual Clinic on Library Applications of Data Processing; ed. by F. W. Lancaster and L. C. Smith, pp. 254-266. Urbana, University of Illinois, Graduate School of Library and Information Science, 1992.

32. METZLER, D. P. Artificial intelligence: what will they think of next? In: Artificial Intelligence and Expert Systems: Will They Change the Library? Proceedings of the 27th Annual Clinic on Library Applications of Data Processing; ed. by F. W. Lancaster and L. C. Smith, pp. 2-49. Urbana, University of Illinois, Graduate School of Library and Information Science, 1992.

33. DAVIES, R. Expert systems and cataloguing: new wine in old bottles? In Expert Systems in Libraries; ed. by F. Gibb, pp. 67-82. London, Taylor Graham, 1986.

34. HORTON, F. W., Jr. Human capital investment: key to the information age. Information and Records Management, 16, 7, 1982, 38-39. 